\title{
Effect of smoking on PEFR: a comparative study among smokers and non smokers in an urban slum community of Hyderabad, India
}

\author{
Gokuldas V. Sawant ${ }^{1}$, Saurabh R. Kubde ${ }^{2}$, Prashant R. Kokiwar ${ }^{3 *}$
}

\author{
${ }^{1}$ Associate Professor, ${ }^{3}$ Professor \& HOD, Department of Community Medicine, Malla Reddy Institute of Medical \\ Sciences, Hyderabad, Telangana, India \\ ${ }^{2}$ Professor, Department of Community Medicine, Malla Reddy Medical College for Women, Hyderabad, Telangana, \\ India
}

Received: 18 November 2015

Accepted: 17 December 2015

\author{
*Correspondence: \\ Dr. Prashant R. Kokiwar, \\ E-mail: kokiwar@gmail.com
}

Copyright: () the author(s), publisher and licensee Medip Academy. This is an open-access article distributed under the terms of the Creative Commons Attribution Non-Commercial License, which permits unrestricted non-commercial use, distribution, and reproduction in any medium, provided the original work is properly cited.

\begin{abstract}
Background: Smoking is hazardous for health. The first impact of smoking is on lungs where it starts decreasing the lung capacity of the smokers. Hence if we can identify this decrease in lung capacity, at an early stage among the smokers, we can try to prevent the further effects of smoking on all body systems. The objective of the study was to study the effect of smoking on PEFR among smokers and compare with age, sex and other facts matched controls (non smokers) in an urban slum community of Hyderabad, India.

Methods: A community based cross sectional comparative study was carried out among 50 smokers and 50 age, sex and other factor matched non smokers. Detailed history was taken. Lung capacity was measured by Wright's peak flow meter as per the standard guidelines. Statistical tests like odds ratio and chi square were used wherever applicable.

Results: The mean age and BMI of smokers and non smokers were comparable. PEFR in smokers was significantly low compared to non smokers. Smoking is strongly associated with the abnormal PEFR. The prevalence of abnormal PEFR was $84 \%$ among smokers as compared to $60 \%$ among non smokers. The smokers were found to be 3.33 times more at risk of having abnormal PEFR than non smokers. This association was statistically significant. $(\mathrm{p}<0.05)$.

Conclusions: The smokers were found to have reduced lung capacity compared to non smokers. Smoking is known to reduce the lung capacity. This study has proved that smoking adversely affects the normal functioning of lungs which leads to increased morbidity and mortality among smokers. Thus smoking was found to be directly related to reduced lung capacity measured in terms PEFR.
\end{abstract}

Keywords: Smoking, PEFR, Lung capacity

\section{INTRODUCTION}

The UN Health Agency reports that about 4.9 million people die each year across the globe due to cigarette smoking. ${ }^{1}$ The death toll is steadily increasing and unless current smoking trends are reversed, this figure is expected to rise to 10 million deaths per year by the 2020 or early 2030 , with $70 \%$ of those deaths occurring in the developing countries. ${ }^{2}$ Cigarette is the leading known risk factor for the development of chronic obstructive pulmonary disease and 50\% of smokers develop clinically significant airflow obstruction. ${ }^{3}$

India is the second largest consumer of tobacco products and third largest producer of tobacco in the world. The adult population of smokers in India is about 84.8 million and is almost equal to the population of Vietnam or Germany. The death toll from tobacco use is projected to rise from 5.4 million in 2004 to 8.3 million in $2030 .{ }^{4}$ The prevalence of tobacco smoking in Indian males is much 
higher (24\%) than females (3\%) according to Global Adult Tobacco Survey (GATS) India 2009-10 report. ${ }^{5}$

However, the prevalence of cigarette smoking in Andhra Pradesh is high in males $(18.5 \%)$ compared to bidi smoking (13.6\%) and cigars, cheroots or cigarillos (4\%). It is noteworthy that the overall prevalence of cigar in India is less than $1 \%(0.6 \%)$ but its prevalence is very high in Andhra Pradesh. ${ }^{5}$

It is difficult to establish national norms in India for healthy men and women as the lung function varies with socio-economic, geographical, climatic, environmental and nutritional conditions. Various authors have used multiple regression analysis to explore the relationship between PEFR and age, height, and weight. ${ }^{6}$ The obstruction to airflow that develops in 15 to $20 \%$ of heavy smokers is thought to be due to abnormalities in airways with less than $2 \mathrm{~mm}$ internal diameter. ${ }^{7}$

It is estimated that around $13 \%$ of cardiovascular disease death are due to tobacco smoking. ${ }^{8}$ Paradoxically several epidemiological studies have found that blood pressure levels among cigarette smokers were the same as or lower than those of non smokers. ${ }^{9,10}$

With the above background, it is clear that smoking is hazardous for health. The first impact of smoking is on lungs where it starts decreasing the lung capacity of the smokers. Hence if we can identify this decrease in lung capacity, at an early stage among the smokers, we can try to prevent the further effects of smoking on all body systems. And as mentioned above, this can be simply and easily measured by PEFR.

Hence present study has been planned to study the effect of smoking on the lung capacity (as measured by PEFR) among smokers and compare with age, sex and other facts matched controls (non smokers) in an urban slum community.

\section{METHODS}

Present study was a community based cross sectional comparative study carried out in an urban slum area of Hyderabad which is a field practice area of Department of Community Medicine, Malla Reddy institute of Medical Sciences, Hyderabad during December 2013 to March 2014.

\section{Ethical considerations}

Institutional Ethics Committee permission was obtained to conduct the study. Informed consent was obtained from every person. At the end of history taking and examination, every subject was imparted health education on hazardous effects of smoking. We tried to motivate them to quit smoking. Those who were found to have any health problems were referred to Urban Health Training Centre.

\section{Sample size}

It was decided to cove 50 smokers and 50 age, sex and other factor matched non smokers.

\section{Sampling technique}

Convenient sampling technique was used to select smokers and non smokers.

\section{Cases and controls}

Smokers were termed as cases and non smokers were termed as controls for the present study purpose.

\section{Matching}

Cass and control were matched for age group interval of five years, sex, occupation and other parameters as listed in the inclusion and exclusion criteria.

Eligibility criteria for cases and controls:

\section{Inclusion criteria}

1. Age $25-50$ years.

2. For cases minimum duration of smoking of 5 years.

3. Willing to participate in the study.

\section{Exclusion criteria}

1. Industrial workers.

2. History of tuberculosis, COPD, Asthma, any other cardiopulmonary diseases, lung cancer, any thoracic/spinal/muscular deformity, history of ARI preceding 6 weeks.

3. Body mass index (BMI) less than 18.5 and more than 25.

4. Passive smokers.

\section{Data collection procedure}

Baseline socio demographic information was collected in the pre designed study questionnaire from smokers initially. Measurements like PEFR, anthropometry, blood pressure were recorded.

Height, weight, waist circumference and hip circumference were measured as per standard guidelines laid down by World Health Organization (WHO). ${ }^{11} \mathrm{~A}$ cut off point of BMI more than or equal to $25 \mathrm{~kg} / \mathrm{m}^{2}$ was taken as risk factor. ${ }^{12}$ Blood pressure was measured and classified as suggested by WHO. ${ }^{13}$

PEFR is a simple method of measuring airway obstruction and it will detect moderate or severe disease. The simplicity of the method is its main advantage. It is measured using a standard Wright Peak Flow meter or mini Wright Meter. The needle was always reset to zero before PEFR is measured. 
Table 1: Normal values of PEFR are related to the patients' height.

\begin{tabular}{|ll|}
\hline Height $(\mathrm{cm})$ & PEFR $(\mathrm{L} / \mathrm{min})$ \\
\hline 120 & 215 \\
\hline 130 & 160 \\
\hline 140 & 300 \\
\hline 150 & 350 \\
\hline 160 & 400 \\
\hline 170 & 450 \\
\hline 180 & 500 \\
\hline
\end{tabular}

Mean $=2 ; \mathrm{SD}= \pm 100$

\section{RESULTS}

A community based cross sectional comparative study was carried out in an urban slum area among 50 smokers and 50 age, sex matched non smokers to study the effect of smoking on PEFR.

Table 2: Distribution of study subjects as per their age.

\begin{tabular}{|llll|}
\hline $\begin{array}{l}\text { Age } \\
\text { (years) }\end{array}$ & Smokers & Non smokers & Total \\
\hline $25-29$ & $13(26)$ & $13(26)$ & $26(26)$ \\
\hline $30-34$ & $07(14)$ & $09(18)$ & $16(16)$ \\
\hline $35-39$ & $14(28)$ & $12(24)$ & $26(26)$ \\
\hline $40-44$ & $10(20)$ & $08(16)$ & $18(18)$ \\
\hline $45-50$ & $06(12)$ & $08(16)$ & $14(14)$ \\
\hline Total & $50(100)$ & $50(100)$ & $100(100)$ \\
\hline
\end{tabular}

*Figures in the parentheses indicate percentages

Table 2 shows age distribution of the study subjects. Both the groups of smokers and non smokers are comparable in their age distribution as they were matched for age groups. Among smokers, maximum study subjects were found in the age group of 35-39 years (28\%) followed by 25-29 years i.e. $26 \%$. Among non smokers, $26 \%$ were in the age group of 25-29 years.

Table 3: Comparison of smokers and non smokers for few specified attributes (values are given in mean+SD).

\begin{tabular}{|c|c|c|c|c|}
\hline Characteristics & Smokers & $\begin{array}{l}\text { Non } \\
\text { smokers }\end{array}$ & $\begin{array}{l}\mathbf{T} \\
\text { value }\end{array}$ & $\begin{array}{l}P \\
\text { value }\end{array}$ \\
\hline Age & $\begin{array}{l}36.2 \pm \\
7.13\end{array}$ & $\begin{array}{l}35.98 \pm \\
7.3\end{array}$ & 0.152 & 0.879 \\
\hline BMI & $\begin{array}{l}22.9 \pm \\
4,25\end{array}$ & $\begin{array}{l}24.07 \pm \\
3.55\end{array}$ & 1.502 & 0.136 \\
\hline PEFR & $\begin{array}{l}311.6 \pm \\
105.99\end{array}$ & $\begin{array}{l}365.4 \pm \\
91.65\end{array}$ & 2.716 & 0.007 \\
\hline SBP & $\begin{array}{l}123.97 \pm \\
16.52\end{array}$ & $\begin{array}{l}125.1 \pm \\
15.61\end{array}$ & 0.351 & 0.725 \\
\hline DBP & $\begin{array}{l}85.24 \pm \\
11.82\end{array}$ & $\begin{array}{l}84.96 \pm \\
8.25\end{array}$ & 0.137 & 0.891 \\
\hline
\end{tabular}

The mean age and BMI of smokers and non smokers were comparable and there was no statistical significant difference in the mean values of them. This is because they were matched for age and BMI.

It can be observed from the above table that the mean PEFR in smokers was significantly low compared to non smokers.

Table 4: Association between smoking and PEFR.

\begin{tabular}{|llll|}
\hline & $\begin{array}{l}\text { Abnormal } \\
\text { PEFR }\end{array}$ & $\begin{array}{l}\text { Normal } \\
\text { PEFR }\end{array}$ & Total \\
\hline Smokers & $42(84 \%)$ & $08(16 \%)$ & $50(100 \%)$ \\
\hline $\begin{array}{l}\text { Non } \\
\text { smokers }\end{array}$ & $30(60 \%)$ & $20(40 \%)$ & $50(100 \%)$ \\
\hline Total & $72(72 \%)$ & $28(28 \%)$ & $\begin{array}{l}100 \\
(100 \%)\end{array}$ \\
\hline
\end{tabular}

$\mathrm{OR}=3.33(95 \% \mathrm{CI}=1.3613-8.999) ; \mathrm{X}^{2}=7.143 ; \mathrm{P}=0.00752$

It can seen from the above table that smoking is strongly associated with the abnormal PEFR. The prevalence of abnormal PEFR was $84 \%$ among smokers as compared to $60 \%$ among non smokers. The smokers were found to be 3.33 times more at risk of having abnormal PEFR than non smokers. This association was statistically significant. $(\mathrm{p}<0.05)$.

It can seen from the above table that smoking is strongly associated with the abnormal PEFR. The prevalence of abnormal PEFR was $84 \%$ among smokers as compared to $60 \%$ among non smokers. The smokers were found to be 3.33 times more at risk of having abnormal PEFR than non smokers. This association was statistically significant $(\mathrm{p}<0.05)$.

\section{DISCUSSION}

Peak expiratory flow rate (PEFR) value can be used as an indicator of a person's health and it is a clinical tool in diagnosis, management and follow up for respiratory diseases. It has been shown that as a person ages, their PEFR decreases. Peak flow measurements can be used to measure the strength of muscles of respiration and thus ca be used to monitor respiratory impairment. Diurnal variation of PEFR is used to diagnose and in the management of bronchial asthma. ${ }^{14}$

PEFR is measured by peak expiratory flow meter which is a simple and relatively cheap device. It has a great diagnostic and prognostic value in patients with hyperactive air way disease. ${ }^{14-16}$

Many factors can affect the reading of PEFR. The age, sex and height are important variables upon which PEFR depends. ${ }^{17}$ Other factors include the diurnal variations ${ }^{18}$ and ethnic differences. ${ }^{19}$ 
One possible reason for the decrease in PEFR could be inflammation which is common and constant pathological finding in cigarette smokers. ${ }^{20}$ Earlier studies have reported that airway flow limitation occurs due to bronchial constriction caused by mediators of inflammation. $^{21}$ Inflammation either directly or by increasing smooth muscle tone, indirectly, may cause airway fibrosis. $^{25}$ All these changes promote wall thickness leading to airway narrowing and flow limitation. ${ }^{22,23}$

The prevalence of abnormal PEFR was $84 \%$ among smokers as compared to $60 \%$ among non smokers. The smokers were found to be 3.33 times more at risk of having abnormal PEFR than non smokers. This association was statistically significant $(\mathrm{p}<0.05)$.

Bajentril AL, Veeranna $\mathrm{N}$ studied that 2-5 years of tobacco smoking tends to a definite tendency to narrowing of both the large and small airways and significantly lowering lung function. ${ }^{24}$ Ferris and Cotes showed a decrease in diffusing capacity in cigarette smokers and this was probably related to a lower pulmonary capillary blood value in smokers compared with non smokers. ${ }^{25}$ Chatterji $\mathrm{S}$ et al found that value of MVV and PEFR is significantly lower in smokers than non smokers. ${ }^{26}$

Padmavathi KM et al reported that MVV showed significant reduction $(\mathrm{p}<0.0001)$ in smokers than non smokers possible due to reduction in respiratory muscle strength. $^{27}$ Mead et al showed that with increasing resistance at the mouth there was a decline in PEFR. ${ }^{28}$ Thus, within an individual subject, PEFR may be influenced by the instrument used for measuring it; however, such an interaction between subject and instrument may not be the same for all subjects. Read et al 29 had assessed ventilator capacity in relation to smoking habits and respiratory symptoms and concluded that among males, smoking in the absence of symptoms even leads to some reduction of ventilator capacity.

\section{CONCLUSION}

The smokers were found to have reduced lung capacity compared to non smokers. Smoking is known to reduce the lung capacity. This study has proved that smoking adversely affects the normal functioning of lungs which leads to increased morbidity and mortality among smokers. Thus smoking was found to be directly related to reduced lung capacity measured in terms PEFR. Thus smoking was found to be directly related to reduced lung capacity measured in terms PEFR.

Funding: No funding sources Conflict of interest: None declared

Ethical approval: The study was approved by the Institutional Ethics Committee

\section{REFERENCES}

1. WHO. United Nations Agency. Pakistan drug updates. An official newsletter of the Ministry of Health, Government of Pakistan, Islamabad. 2003;5:16.

2. WHO. A global status report, anonymous. Tobacco or health: WHO, Geneva. 1997;115-7.

3. Lundback B, Lindberg A, Lindstrom M, Ronmark E, Jonsson AC, Jonsson E, et al. Not 15 but $50 \%$ of smokers develop COPD? Report from the obstructive lung disease in northern Sweden studies. Obstructive lung disease in Northern Sweden studies. Respire Med. 2003;97(2):115-22.

4. Mathers CD. The global burden of disease: 2004 update. WHO Geneva, 2008.

5. Global Adult Tobacco Survey. GATS India 2009-10 Report. Ministry of Health and Family Welfare, Government of India, New Delhi, 2010.

6. Mathur N, Rastogi SK, Hussain T, Gupta BN. Lung function norms in healthy working women. India $\mathrm{J}$ Physiol Pharmacol. 1998;42:245-51.

7. Hogg JC, Macklem PT, Thurlbeck MW. Site and nature of airway obstruction in chronic obstructive lung disease. New Engl J Med. 1968;278(25):135560.

8. Begg, Vos ST, Barker B, Stevenson C, Stanley L, Lopez AD. The burden of disease and injury in Australia. 2007;PHE 82.

9. Berglund G, Wilhelmsen L. Factors related to blood pressure in a general population sample of Swedish men. Acta Med Scand. 1975;198(4):291-8.

10. Seltzer CC. Effect of smoking on blood pressure. Am Heart J. 1974;87(5):558-64.

11. WHO. Physical status: the use and interpretation of anthropometry. WHO Tech Rep Series. 1995;854:424-38.

12. Park K. Park's Textbook of Preventive and Social Medicine. $18^{\text {th }}$ ed. $\mathrm{m} / \mathrm{s}$ Banarasidas Bhanot Publishers, Jabalpur, 2005.

13. World Health Organization. Hypertension control. WHO Tech Rep Series. 1996;862.

14. Katz DN. The mini Wright peak flow meter for evaluating airway obstruction in a family practice. $\mathbf{J}$ Fam Pract. 1983;17:51-7.

15. British Thoracic Association. Death from asthma in two regions of England. British Med J. 1982;285:1251-5.

16. Battu K, Collins-Wiliams C, Zaleskey C. Evaluation of home monitoring of asthmatic children with the mini Wright peak flow meter. J Asthma. 1982;19(1):33-7.

17. British Thoracic Society. Research unit of the Royal College of Physicians of London. Guidelines for the management of asthma in adults with chronic persistent asthma. British Med J. 1990;301:651-3.

18. Gregg I, Nunn AJ. Peak expiratory flow in normal subjects. Br Med J. 1973;3(5874):282-4. 
19. Cinkotai FF, Sharpe TC, Gibbs AC. Circadian rhythms in peak expiratory flow rate in workers exposed to cotton dust. Thorax. 1984;39(10):759-65.

20. Vanhoutte PM. Airway epithelium and bronchial reactivity. Can J Physiol Pharmacol. 1987;65:44850 .

21. Berend N. Lobar distribution of bronchiolar inflammation in emphysema. Am Rev Respir DIis 1981;124:218-20.

22. Piqueras MG, Cosio MG. Disease of the airways in chronic obstructive pulmonary disease. Eur Respir J. 2001;18(Suppl 34):41s-49s.

23. Wright JL, Hobson J, Wiggs BR, Pare PD, Hogg JC. Effect of cigarette smoking on structure of the small airways. Lung. 1987;165:91-100.

24. Bajentri AL, Veeranna N. Effect of 2-5 years of tobacco smoking on ventilator function test. J Indian Medial Assoc. 2003;1017:96-7.

25. Van Ganse WF, Ferris BG, Cotes JE. Cigarette smoking and pulmonary diffusing capacity (transfer factor). Am Rev Resp Dis. 1972;105:30.
26. Chatterjee S, Nag SK, Dey SK. Spirometric standards for non smokers and smokers of India (eastern region). Japanese J Physiol. 1988;38:283-98.

27. Geijer RM, Sachs AP, Hoes AW, Salome PL, Lammers JW, Verheij TJ. Prevalence of undetected persistent air flow obstruction in male smokers of 4065 years old. J Fam Pract. 2005;22(5):485-9.

28. Kim WD, Saettam M, Ghezzo H. Loss of alveolar attachments in smokers. A morphometric correlate of lung function impairment. Am Rev Respir Dis. 1985;132:814-900.

29. Padmavathi KM. Comparative study of pulmonary function variables in relation to type of smoking. Indian J Physiol Pharmacol. 1967;22:95-108.

Cite this article as: Sawant GV, Kubde SR, Kokiwar PR. Effect of smoking on PEFR: a comparative study among smokers and non smokers in an urban slum community of Hyderabad, India. Int J Community Med Public Health. 2016;3:246-50. 